INHIBITORY CONTROL AND CORRECTIVE FEEDBACK TIMING

\begin{abstract}
This article reports a study investigating the role of inhibitory control in the acquisition of Spanish noun-adjective gender agreement under different feedback timing conditions. Fortythree Spanish learners completed a communicative task through synchronous computer-mediated communication. The immediate group received reformulations immediately after their errors, whereas the delayed group received reformulations at the end of the task. The control group did not receive any feedback. Learners' knowledge of the target form was assessed using oral production and grammaticality judgment tests at three different times: once before the treatment, once immediately after the treatment, and once ten days after the treatment. Inhibitory control was measured with the Flanker test. Results did not show a statistically significant interaction between inhibitory control and feedback timing group on either outcome measure even though the correlations between learners' gains and inhibitory control were different across groups. Keywords: Inhibitory control, aptitude-treatment interaction, corrective feedback, feedback timing, computer-mediated communication
\end{abstract}




\section{The interaction between inhibitory control and corrective feedback timing}

Interaction in a second language (L2), especially when it includes corrective feedback, has been claimed to be beneficial for L2 acquisition (Long, 1996). Previous studies synthesizing the research on the effectiveness of corrective feedback (Goo, Granena, Yilmaz \& Novella, 2015; Li, 2010; Mackey \& Goo, 2007; Nassaji, 2016; Yilmaz, 2016) have substantiated this claim. Recently, the focus of corrective feedback research has shifted from investigating the effectiveness of corrective feedback to investigating factors that reduce or enhance the influence of feedback on L2 acquisition. Several factors, including feedback type (e.g., Ellis, Loewen \& Erlam, 2006), linguistic target type (e.g., Yilmaz, 2012), cognitive individual differences (e.g., Yilmaz \& Granena, 2016; Granena \& Yilmaz, 2018), task characteristics (e.g., Révész \& Han, 2006), and communication mode (e.g., Yimaz, 2012) have been found to impact the effectiveness of feedback. The current study investigated the interaction between two such factors. The first is feedback timing, which refers to the timing of feedback relative to the learner's non-target-like production. Feedback is considered immediate when provided immediately after the error and delayed when provided at the end or several days after the activity during which the error occurred. An investigation of the role of feedback timing has pedagogical implications because it could inform teachers whether they should provide corrective feedback during a communicative task or reserve it for a later time. The second factor is inhibitory control, which refers to the ability to attend selectively to relevant information by suppressing irrelevant information. In recent years, cognitive abilities such as inhibitory control have drawn much scholarly attention within the aptitude-treatment interaction research paradigm, which has two important goals: (a) determining the instructional option that best fits 
learners' cognitive strengths; (b) collecting indirect evidence about how learning takes place under different instructional conditions. Goal (a) has pedagogical value because it is motivated by a desire to gain maximum benefit from instructional practices. Goal (b) is more theoretical and based on the underlying logic that a positive association between a cognitive ability and learning outcomes under a specific condition would mean that the cognitive ability contributes to the mental processes engaged by the instructional condition (DeKeyser, 2012). Guided by the aptitude-treatment interaction research paradigm, the current study investigates the nature of the relationship between inhibitory control and the effectiveness of two different feedback timing conditions (i.e., immediate and delayed) on errors that occur during synchronous computermediated communication (SCMC).

\section{Background}

\section{Synchronous computer-mediated communication and feedback}

Text-based SCMC refers to real-time communication between people using text-based chat software. It has been argued that text-based SCMC is a hybrid modality carrying the features of both oral and written communication. SCMC involves short turns, real-time communication, informal discourse, and unnoticed grammar errors, features typically associated with oral communication (Smith, 2003; Warschauer, 1997). Several other features, which are more closely linked to written communication, such as longer processing time, visual saliency, and re-readability of messages, separate SCMC from oral communication (Smith, 2003; Sotillo, 2000). Researchers (e.g., Warschauer, 1997) have argued that this second set of features could optimize L2 acquisition by slowing down the pace of the interaction and allowing learners to pay more attention to their output and to notice L2 forms in the input. In fact, research has provided supporting evidence for this position showing that learners focus their attention on form. For 
instance, they self-correct their errors, correct other learners' errors, ask each other the meanings of words and discuss metalinguistic rules (Blake, 2000; Iwasaki \& Oliver, 2003; Yilmaz, 2011). In addition, a meta-analysis (Ziegler, 2015) has revealed that computer-mediated interaction leads to slightly more $\mathrm{L} 2$ gains than face-to-face interaction $(d=.13)$.

SCMC research has also focused on the role of specific interactional features, such as corrective feedback, in L2 acquisition. Studies investigating native speaker-learner (e.g., Gurzynski-Weiss \& Baralt, 2014) or learner-learner (e.g., Yilmaz, 2011) interaction through SCMC have shown that implicit reformulations (or recasts) are the most frequent corrective feedback type. Reformulations restate learners' non-target-like productions into a target-like form and include feedback types such as recasts (i.e., target-like reformulations of learners' non-target-like productions), explicit correction (i.e., explicit rejection of the learner's production, followed by the provision of the target-like form), and metalinguistic correction (i.e., metalinguistic comments about the accuracy of the learner's non-targetlike production, followed by the provision of the target-like form). Ranta and Lyster (2007) contrasted them with prompts, which do not provide target-like input. Reformulations can vary in implicitness/explicitness: those conveying metalinguistic information (e.g., metalinguistic corrections) and/or directly informing learners about the accuracy of learners' production (e.g., explicit correction) are considered explicit, whereas those that provide neither type of information are considered implicit. In the present study, we focused on implicit reformulations based on the empirical evidence (Gurzynski-Weiss \& Baralt, 2014; Yilmaz, 2011) that they are the most frequent feedback type used in text-based SCMC.

Implicit reformulations have received theoretical support from the Interaction Hypothesis (Long, 1996), which suggests that conversational interaction facilitates language acquisition by 
providing learners with linguistic data indicating what is possible (i.e., positive evidence) and what is not possible (i.e., negative evidence) in the target language. Interactionist researchers (e.g., Gass \& Mackey, 2006; Long, 2007) argue that immediate reformulations offer an advantage that most other feedback forms cannot: Due to their unobtrusive nature, they can provide negative evidence without being face threatening or compromising the meaning-based nature of the interaction.

Previous research into the effectiveness of implicit reformulations has provided evidence that implicit reformulations through SCMC can lead to significant pretest-to-posttest learning gains (Sachs \& Suh, 2007) and significantly more gains than no-feedback control groups (Yilmaz, 2012; but see Loewen \& Erlam, 2006 for negative findings for implicit reformulations). There is also evidence that implicit reformulations through SCMC result in better posttest performance than implicit reformulations through face-to-face communication (Yilmaz, 2012; Yilmaz \& Yuksel, 2011). Baralt (2013), however, has shown that the superiority of SCMC reformulations over Face-to-Face Communication (FTFC) reformulations is limited to contexts where feedback is provided during a cognitively simple task. Implicit reformulations in all these studies were provided immediately after learners' errors.

There is much less research focusing on the presence and effectiveness of delayed reformulations in text-based SCMC. One previous study (Bower \& Kawaguchi, 2008) demonstrated that Japanese-English tandem partners provided delayed reformulations to each other using emails after an interaction between them that took place through SCMC. However, Bower and Kawaguchi (2008) did not address the question of whether these delayed reformulations were effective in producing L2 gains. The issue of whether delayed implicit reformulations can be an effective feedback strategy in SCMC contexts was the focus of two 
recent studies (Arroyo \& Yilmaz, 2018; Shintani \& Aubrey, 2016), which we review in the next section after providing a pedagogical and theoretical discussion concerning the role of feedback timing.

\section{Feedback Timing in SCMC}

Researchers (Doughty, 2001; Long \& Robinson, 1998) advocating a focus on form approach have presented theoretical arguments motivating the investigation of the role of timing in feedback effectiveness. A fundamental premise of the focus on form approach is that learners' attention should be briefly drawn to language features during a communicative activity when an observed need warrants such an intervention. One way of focusing learners' attention on form is the provision of implicit reformulations in response to learners' non-target-like utterances. Doughty (2001) has argued that implicit reformulations become useful for learners' developing system through a mental process called cognitive comparison, which involves learners comparing their intention, output, and the input carrying the feedback in their working memory. Doughty (2001) has stated that the success of this cognitive comparison depends on whether the feedback is provided within a cognitive window of opportunity because of limitations on memory capacity. She hypothesized that "with regard to the timing of the information to be compared, the most efficient means to promoting cognitive comparison would seem to be provision of immediately contingent recasts" (p. 253).

Previous research has investigated whether timing moderates the effectiveness of feedback in face-to-face communication. The results of this research were inconclusive, with some studies (e.g., Li, Zhu \& Ellis, 2016, Shintani \& Aubrey, 2016) showing an advantage for immediate feedback and others showing no difference between conditions (e.g., Henderson, 2019; Quinn, 2014). More than that, the results of face-to-face communication studies may not 
be generalized to contexts where feedback is provided during or after text-based SCMC tasks. The learning environment in text-based SCMC is different from that in face-to-face communication because the text-based nature of SCMC provides learners with more processing time as well as more monitoring and revision opportunities. It is possible for these features to interact with the effect of feedback timing given that they could provide possible advantages for noticing and subsequent L2 acquisition.

More closely related to the present study, Shintani and Aubrey (2016) investigated how feedback timing impacted the effectiveness of written feedback provided on hypothetical conditionals in English during two written tasks completed via Google Docs. During the treatment, the synchronous group received immediate text-based feedback via the comment box function of Google Docs. The asynchronous group received delayed feedback via the comment box ten minutes after they completed the task. Their results indicated that although both groups outperformed the control group on the immediate posttest, only the synchronous group outperformed the control group on the delayed posttest. It should be noted that Shintani and Aubrey's treatment task was monologic in the sense that it did not necessarily require learners and the researcher to work together to complete the task. This lack of communicative interaction might have helped the recognition of the corrective function of the feedback because the researchers' messages served only for the purpose of correcting learners' errors.

To the best of our knowledge, Arroyo and Yilmaz (2018), whose data set partially overlap with the one used in the present study, is the only study that investigated feedback timing in the context of a dialogic text-based SCMC task. The study examined the role of immediate and delayed implicit reformulations on the acquisition of Spanish noun-adjective gender agreement. The results showed that immediate reformulations were more effective than delayed 
reformulations in leading to learning gains as measured by an oral production test, but feedback timing did not play a role in learning gains on a grammaticality judgment test. In sum, both studies found an advantage for the immediate feedback provided during a text-based computermediated task. However, no study so far has investigated whether inhibitory control can be linked to learners' performance under different feedback timing conditions.

\section{Inhibitory Control}

Executive functions that are used to control thoughts and actions have been considered key mechanisms in many models of cognition. For example, Baddeley's (1986) working memory model included a domain-general "central executive" performing executive functions such as updating, task switching, and inhibition along with domain-specific storage components (e.g., phonological loop). Similarly, Norman and Shallice's (1986) Supervisory Attentional System (SAS) includes an attention control mechanism that is responsible for performing executive functions such as regulating non-routine and novel tasks especially when the task requires error correction or planning, or the suppression of a strong, habitual response. One executive function that might be crucial for L2 performance and learning is inhibitory control, or the ability to suppress irrelevant information for a given task in order to facilitate attention to relevant information.

The role of inhibitory control in bilinguals' language processing has attracted much attention in L2 psycholinguistics research. Researchers have investigated the relationship between inhibitory control and success in various language tasks inspired partly by Green's (1998) Inhibitory Control Model, which states that non-target lexical items are inhibited to make the comprehension and production of the target language possible. Inhibitory control has been 
found to be related to the perception and production of L2 phonological segments (Darcy, Mora, \& Daidone, 2016). Also, inhibitory control has been found to be correlated with auditory comprehension among bilinguals, but not among monolinguals (Blumenfeld \& Marian, 2011). Other psycholinguistic studies (Bialystok, E., Martin, M. M. \& Viswanathan, M., 2005; Costa, Hernandez, \& Sebastián-Gallés, 2008) showed that bilingual children and adults perform better than their monolinguals counterparts on tasks measuring inhibitory control, raising the possibility that managing competing languages enhances inhibitory control. Bartolotti, Marian, Schoeder, and Shook (2011), using the statistical learning paradigm, showed that inhibitory control facilitates successful word segmentation of an artificial language based on the International Morse Code alphabet when there is interference from another language.

Individual differences in inhibitory control have been most commonly measured by tasks such as the Simon, Stroop, or Flanker, which focus on the effects of irrelevant information on performance. The level of performance in a typical version of these tasks is gauged by response times of test takers in identifying the correct aspect of the stimuli (ink color of words in the Stroop, color of objects in the Simon, and direction of an arrow in the center of a group of arrows in the Flanker), without being distracted by the aspect of the stimuli irrelevant for task completion (the meaning of the word in the Stroop, the location of boxes in the Simon, and the direction of other arrows in the Flanker).

The role of inhibitory control has also been studied with beginner- and intermediate-level language learners studying an L2 in an instructed setting. Gass and Lee (2011) argued that inhibitory control could be relevant for L2 acquisition because successful L2 use requires one to inhibit information from competing languages or domains of language (e.g., syntax, semantics, phonology). However, their study did not show a relationship between inhibitory control, as 
measured by L1 and L2 Stroop tasks, and first- and third-year Spanish learners' proficiency. Linck and Weiss (2015) investigated whether inhibitory control as measured by a Simon task was predictive of L2 learners' development in Spanish after a semester-long introductory-level course as demonstrated through changes in proficiency between two testing times. Their results did not show a predictive role for inhibitory control. These results raise the possibility that inhibitory control may not play a role in L2 proficiency when proficiency is measured by coarsegrained measures, such as the institutional status of learners as in Gass and Lee (2012) or a test measuring multiple grammatical and vocabulary forms via a limited number of items as in Linck and Weiss (2015). Additionally, given the fact that these studies focused on L2 attainment after at least one semester of exposure to the language in an instructed context, it may be that inhibitory control is not an important factor in long-term attainment. One cannot assume, however, that the role of inhibitory control would be the same in short-term L2 attainment under controlled conditions when a single target structure is the focus of the study, as in Gass, Behney, and Uzum (2013).

Gass et al. (2013) examined the role of inhibitory control in the extent to which Englishspeaking learners of Italian benefited from oral feedback, following a pretest-posttest design. The target form in Gass et al. was Italian noun-adjective gender and number agreement. The pretest and the posttest involved a picture description task. The learners carried out an interactive objectplacement task during the treatment phase and received interactional feedback on errors involving the target form. Learners' inhibitory control was measured with two Stroop tasks, one in the L1 and one in the L2. The results revealed that learners with high inhibitory control benefited more from the conversational interaction including corrective feedback than learners with low inhibitory control. 
Overall, the above literature review suggests that inhibitory control is related to the perception and production of phonological segments, auditory comprehension, and auditory word segmentation in the L2. Although some studies (Gass \& Lee, 2011; Linck \& Weiss, 2015) did not find a link between inhibitory control and proficiency, one study (Gass et al., 2013) showed that inhibitory control was related to the extent to which learners benefit from corrective feedback in the context of oral interaction. To the best of our knowledge, however, no study has investigated whether inhibitory control is related to the extent to which learners take advantage of feedback provided on errors that arise during text-based SCMC interaction.

\section{Present Study}

Although few studies have investigated the role of feedback timing in text-based SCMC (Arroyo \& Yilmaz, 2018; Shintani \& Aubrey, 2017), the existing evidence suggests that immediate feedback is more beneficial than delayed feedback for L2 learning. However, there is a lack of research about the extent to which the role of feedback timing is modulated by inhibitory control. Learners may need inhibitory control when learning through corrective feedback in the context of interaction. According to many researchers (e.g., Doughty, 2001; Schmidt, 2001), learning from corrective feedback in the form of reformulations depends on whether learners can notice the discrepancy between their non-target-like utterance and the target-like utterance carried by the feedback. For such noticing to take place, Gass et al. (2013) argued, learners need to "suppress irrelevant information and focus on the source of the feedback" (p. 109) when confronted with multiple types of information typical in an interactive context. Furthermore, when learners perform an interactive task with an interlocutor requiring them to produce language and understand the interlocutor's messages, it can be cognitively challenging for them to pay attention to corrective feedback. In such contexts, learners must 
prioritize where they need to direct their attention because a focus on form and a focus on meaning compete as argued by Skehan (1998). One can hypothesize then that learners should draw on their inhibitory control to benefit from feedback provided immediately after their errors during an interactive task by suppressing their processing for meaning and selecting the feedback as the object of attention. If, however, feedback is provided at the end of the communicative task in a delayed fashion, there may be fewer sources of distraction requiring the use of one's inhibitory control because there will be no communicative pressure in such a situation.

The present study investigated whether inhibitory control has an impact on the acquisition of Spanish noun-adjective gender agreement through immediate or delayed reformulations. Our research question was: How is inhibitory control related to learners' improvement on Spanish noun-adjective gender agreement in different feedback timing conditions?

\section{Method}

The present experimental study followed a pretest-posttest-delayed-posttest design. The dependent variable was L2 Spanish learners' gains in noun-adjective gender agreement in Spanish, operationalized as the gain scores received on an oral production test (OPT) and grammaticality judgment test (GJT) in the posttest and delayed posttest. The independent variables were inhibitory control, measured by an Eriksen Flanker task (1974), and feedback timing, which had three levels: immediate, delayed, and control. The participants were randomly assigned to the immediate feedback, delayed feedback, or control group.

\section{Participants}

The initial pool of participants included forty-five adult L2 Spanish learners who speak English as their L1. They were undergraduate students at a large public Midwestern U.S. 
university and were attending or had previously attended Spanish courses offered at the university. After cleaning the data for outliers, the final number of participants for the present study was 43 (8 male and 35 female). The participants' ages ranged between 18 and 28 years ( $M$ $=20.32 ; S D=2.32)$, and on average, they had $2.46(S D=.77)$ semesters of Spanish instruction at the undergraduate level. Seventeen percent of the participants also reported knowing a third language (i.e., Vietnamese, Italian, French, American Sign Language, German, and Hebrew) at a beginner to intermediate level.

A video-retell task was administered as an independent measure of proficiency. In this task, learners were asked to watch a 90-second video and retell its events in Spanish in one minute (see Arroyo \& Yilmaz, 2018 for scoring details). The results of a one-way ANOVA used to determine the comparability of the groups' proficiency scores revealed no significant differences among the groups, $F(2,40)=.379, p=.687, \eta^{2}=.019$ (immediate, $M=5.56, S D=$ 1.67; delayed, $M=5.14, S D=1.25$; control, $M=5.51, S D=1.16$ ).

\section{Target Structure}

The target structure of this study was Spanish noun-adjective gender agreement. Spanish marks gender for nouns, adjectives, and determiners, and adjectives agree with the nouns they modify. When there is overt gender morphology, gender is marked with the ending /-o/ for masculine nouns and /-a/ for feminine nouns. There are also morphologically unmarked nouns for gender (e.g., la verdad [truth-F]). Most adjectives take the masculine /-o/ or feminine /-a/ ending depending on the gender of the noun they modify. Spanish exhibits both attributive and predicate adjective agreement. Example 1a shows an example of intra-phrasal agreement in which adjective agreement is within the noun phrase. Example 1b illustrates an inter-phrasal agreement in which the agreement is between phrases. 
Example 1: Noun-adjective gender agreement in Spanish

a. El bolso nuevo (The-M purse-M new-M)

"The new purse"

La casa nueva (The-F house-F new-F)

"The new house"

b. El libro es negro (The-M book-M is black-M)

"The book is black."

La camisa es negra (The-F shirt-F is black-F)

"The shirt is black."

\section{Treatment task}

During the treatment, each participant completed a one-way information-gap picture description activity with a native speaker of Spanish at a research laboratory (Arroyo \& Yilmaz, 2018 to view the treatment materials). The native speaker and the participant used different computers facing opposite directions, and the interaction was carried out through Skype's textchat feature. Both interlocutors were given a Microsoft PowerPoint file that included 12 slides. The slides of the participant contained two pictures of various objects, and the pictures on each slide were different from each other in terms of the objects' physical features (i.e., color, shape, and size). The slides of the native speaker were different from the participant's slides in that the objects that could be seen in the participant's slides had been deleted from the native speaker's pictures. Instead of these objects, the native speaker could see empty boxes and three alternative versions of the deleted objects (e.g., blue car, white car, yellow car) under each box. The participant was asked to describe each picture to help the native speaker choose the correct version of the object based on the description. 


\section{Feedback treatment}

All learners performed the treatment task, but the control group $(N=15)$ did not receive any feedback during or after the task. The immediate feedback group $(N=15)$ received implicit reformulations within 40 seconds after they produced a non-target-like utterance including a gender agreement error. The delayed feedback group $(N=13)$ received implicit reformulations via a Microsoft Word document after they finished the treatment task. Example 2 shows how the native speaker provided feedback to a learner in the immediate feedback group.

Example 2: Immediate Feedback Episode During the Task

Learner: *En el imagen 1: La guitarra es amarillo.

"In (picture) one, the guitar is yellow."

Experimenter: Guitarra es amarilla.

"Guitar is yellow."

Experimenter: Qué más?

"What else?"

Learner: Uno... el libro es negro.

"(In picture) one, the book is black."

As shown in Example 2, the native speaker asked the participant to talk about other objects after providing a reformulation. This strategy was used throughout the treatment to prevent the immediate feedback group from repairing their non-target-like utterances in their next turn, and thus control repair opportunities. This strategy was necessary because learners receiving delayed feedback were not expected to repair their errors as they received feedback at the end of the treatment task. 
Example 3: Errors in the delayed feedback condition during the treatment

Learner: *Endos, la guitarra es negro.

"In (picture) two, the guitar is black."

Experimenter: siguiente imagen

"next picture"

Learner: Imagen uno tiene un libro

"Picture one has a book"

Example 4: Delayed feedback after the treatment task

Learner: *guitarra es negro

"guitar is black"

Experimenter: guitarra es negra

"guitar is black"

Errors of the learners in the delayed feedback condition were ignored during the treatment task as shown in Example 3. The native speaker, however, transferred these errors to a Microsoft Word file and added a target-like reformulation for each error below the line containing the error. At the end of the treatment task, learners were presented with this document and instructed to read through it within five minutes. Neither the immediate nor the delayed feedback included textual enhancement such as bolding or italicization.

\section{Language Measures}

A GJT and OPT were used in the pretest, posttest I, and posttest II to measure learner's accuracy in Spanish gender agreement. The GJT included a list of 48 (24 target items, 24 distractors) sentences in Spanish. Learners were asked to decide whether each sentence was grammatically correct and provide correction for the errors in ungrammatical items. The items 
were balanced for gender (feminine or masculine), morphological marking (overt and non-overt), and grammaticality (grammatical or ungrammatical). The OPT required learners to view sets of two pictures in a PowerPoint file and describe the differences between them orally. The objects in the pictures differed from each other in terms of shape, color, and size. There were 48 (24 target items, 24 distractors) items in the OPT, and learners were asked to respond to each picture as quickly as possible. The items were balanced for gender and morphological marking. In both outcome measures, we controlled for the agreement context by only including contexts for intraphrasal agreement.

Three different versions of each measure were created, and a different version was used at each testing time (pretest, posttest I, posttest II). To control for possible order effects, these versions were counterbalanced within each experimental condition in a Latin square design.

Responses to GJT items were coded for accuracy. Learners received 1 point after correctly identifying grammatical sentences or after correctly identifying ungrammatical sentences and providing an accurate correction. Accuracy rate scores for grammatical and ungrammatical items were calculated separately by dividing the sum of accurate responses by the total number of items in each category (maximum possible score $=1.0$, minimum possible score 0). Grammatical items were not included in the statistical analysis because they were associated with low internal consistency as shown by Cronbach's alpha values (version $\mathrm{A}=.20$; version $\mathrm{B}$ $=.05$; version $\mathrm{C}=.10$ ) Cronbach's alpha values for the ungrammatical items in GJTs were deemed acceptable (version $\mathrm{A}=.61$, version $\mathrm{B}=.72$, version $\mathrm{C}=.67$ ).

Responses to OPT items were transcribed and coded for accuracy in gender agreement. Each correctly marked adjective received 1 point, and each incorrectly marked adjective received 0 . Two native Spanish speakers listened to and coded $10 \%$ of the data, and their agreement was 
99.2\% for adjective marking. Next, accuracy rate scores were calculated by dividing the number of accurate answers by the total number of obligatory contexts (maximum possible score $=1.0$, minimum possible score 0 ).

\section{Eriksen Flanker Task}

This study employed a modified version of the Eriksen Flanker Task (1974) to measure the participants' inhibitory control. This nonverbal task is used to measure participants' ability to ignore irrelevant stimuli to make fast decisions. In this computer-delivered choice reaction time (RT) task, the participants were instructed to pay attention to a stimulus (i.e., arrow $\rightarrow$ ) in the center of the screen, which was accompanied by distracting (incongruent) arrows, facilitating (congruent) arrows, or neutral stimuli (i.e., approximation symbol ). The participants were asked to make a simple response by pressing the arrow key (i.e., < vs. >) on the keyboard that matches the arrow they see in the center of the screen while trying to ignore the other stimuli (See Figure 1). Five sample trials were presented to the participants before starting the task. The experiment involved 120 trials with 40 congruent, 40 incongruent, 40 neutral trials, and the trials were counterbalanced. RTs are expected to be faster for congruent stimuli and slower for incongruent stimuli. As a result, smaller differences between congruent and incongruent stimuli indicate higher inhibitory control.

To analyze the data from the Flanker test, we first examined the data for accuracy to identify learners with an error rate of $10 \%$ or higher. Two participants' data, one for being three standard deviations above the mean and the other for including 51\% error rate, were excluded from the dataset, and further statistical analyses were conducted with 43 participants. Next, incorrect responses for each trial were identified and excluded from the RT data. Descriptive statistics were calculated for RTs for congruency, incongruency, and neutral conditions. 
Subsequently, these RTs were checked for outliers based on Jiang's (2012) RT data analysis guidelines. First, each participant's average RT and standard deviation were computed. The outliers, RTs with two standard deviations below and above the mean of the same participant, were excluded from the RT data. After cleaning the outliers, Flanker scores were calculated for each participant. Inhibitory control was operationalized as the RT for correct responses in incongruent trials minus the RT for correct responses in neutral trials (Gass et al., 2013; Kane \& Engle, 2003).

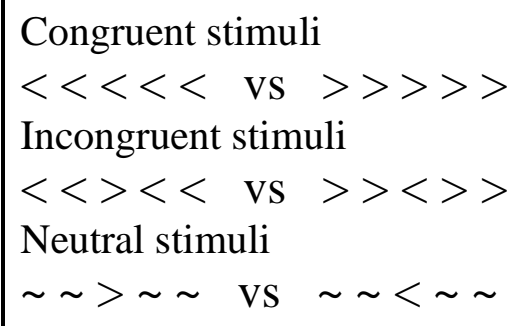

Figure 1. Flanker task stimuli types

\section{Procedure}

The study took place in a research lab in two sessions. The first session involved the administration of the proficiency test (video re-tell), pretest, the treatment, and posttest I. The second session took place ten days after the first session and included the administration of posttest II, the Flanker task, and a background questionnaire. The OPT was completed before the GJT in each session.

\section{Results}

To determine whether the treatment groups were comparable with respect to their inhibitory control scores, a one-way ANOVA was performed on inhibitory control scores (control, $M=42.08, S D=22.84$; immediate, $M=39.82, S D=18.25$; delayed, $M=55.64, S D=$ 25.47). The test revealed no differences between the groups, $F(2,40)=2.02, p=.15$, indicating 
that groups were roughly equivalent in their inhibitory control scores. Next, two gain scores, one for the difference between pretest and posttest I (gain I) and one for the difference between pretest and posttest II (gain II) were calculated for each group and outcome measure (OPT and GJT). Next, in order to determine whether inhibitory control interacted differently with the gain scores of each condition, a custom analysis of covariance (ANCOVA) model for each test and gain score type (gain I or gain II) was carried out. Feedback group was the independent variable, and inhibitory control was the covariate in these analyses. The models also included the interaction between inhibitory control and group. Additional ANCOVA models were run if the custom-models revealed non-significant covariate-treatment interactions to see whether the covariate has a significant effect on scores regardless of the treatment condition.

Mean accuracy rate scores and standard deviations for all groups on the OPT appear in Table 1. As explained in the methods section, we calculated accuracy rate scores by dividing the sum of accurate responses by the total number of items. The immediate group improved the most in both posttest I and posttest II. The gains of the delayed group were very small and indistinguishable from the gains of the control group. The ANCOVA with the interaction term revealed a significant group effect, $F(2,37)=4.28, p=.020, \eta^{2}=.077$, and non-significant inhibitory control, $F(1,37)=3.29, p=.078, \eta^{2}=.029$, and inhibitory-control-by-group interaction effects, $F(1,37)=1.22, p=.306, \eta^{2}=.022$. The ANCOVA without the interaction term revealed a significant group, $F(2,39)=11.47, p<.001, \eta^{2}=.209$, and inhibitory control effects, $F(1,39)=4.396, p=.043, \eta^{2}=.040$. Bonferroni-adjusted pairwise comparisons of adjusted means revealed that the immediate group outperformed both the control $(M D=.202, p$ $<.001, d=1.649)$ and the delayed group $(M D=.167, p=.004, d=1.363)$, but there was no difference between the delayed and control groups $(M D=.036, p=1.000, d=.293)$. 
Table 1

Descriptive Statistics for the Oral Production Test

\begin{tabular}{|c|c|c|c|c|c|c|c|c|c|c|}
\hline \multirow[t]{2}{*}{ Group } & \multicolumn{2}{|c|}{ Pretest } & \multicolumn{2}{|c|}{ Posttest I } & \multicolumn{2}{|c|}{ Posttest II } & \multicolumn{2}{|l|}{ Gain I } & \multicolumn{2}{|l|}{ Gain II } \\
\hline & $M$ & $S D$ & $M$ & $S D$ & $M$ & $S D$ & $M$ & $S D$ & $M$ & $S D$ \\
\hline Control $(n=15)$ & .56 & .10 & .60 & .14 & .56 & .13 & $.04(.04)$ & .12 & $.00(.00)$ & .15 \\
\hline Immediate $(n=15)$ & .49 & .10 & .72 & .12 & .69 & .12 & $.24(.25)$ & .11 & $.20(.20)$ & .14 \\
\hline Delayed $(n=13)$ & .54 & .11 & .63 & .14 & .57 & .11 & $.09(.08)$ & .15 & $.03(.05)$ & .13 \\
\hline
\end{tabular}

Note. Minimum possible score $=0$; maximum possible score $=1.0$. Values appearing in parentheses are adjusted means

The ANCOVA model for oral production gain II scores with the interaction term revealed a significant group effect, $F(2,37)=4.52, p=.017, \eta^{2}=.117$, and non-significant inhibitory control, $F(1,37)=.71, p=.406, \eta^{2}=.008$, and inhibitory-control-by-group interaction effects, $F(1,37)=2.319, p=.113, \eta^{2}=.060$. The ANCOVA without the interaction term revealed a significant group effect $F(2,39)=8.191, p=.001, \eta 2=.226$, and a non-significant inhibitory control effect, $F(1,39)=.263, p=.611, \eta^{2}=.003$. Pairwise comparisons run on adjusted means revealed that the immediate group outperformed both the control $(M D=.199, p$ $=.001, d=1.443)$ and the delayed group $(M D=.142, p=.038, d=1.030)$, but there was no difference between the delayed and control groups $(M D=.057, p=.895, d=.413)$.

Mean accuracy rate scores and standard deviations for all groups on the ungrammatical items of the GJT appear in Table 2. the immediate and delayed groups made similar gains, and the gains of these groups were higher than those of the control group. The ANCOVA model with the interaction term carried out for gain I scores revealed no significant effects: group, $F(2,37)$ 
$=.32, p=.726, \eta^{2}=.006$; inhibitory control $F(1,37)=1.82, p=.185, \eta^{2}=.018 ;$ inhibitorycontrol-by-group interaction, $F(1,37)=.953, p=.395, \eta^{2}=.019$. The ANCOVA without the interaction term revealed a significant group effect, $F(2,39)=10.267, p<.001, \eta 2=.205$, and a non-significant inhibitory control effect, $F(1,39)=1.32, p=.257, \eta 2=.013$. Bonferroniadjusted pairwise comparisons run on adjusted means revealed that both the immediate $(M D=$ $.259, p<.001, d=1.606)$ and delayed groups $(M D=.194, p=.012, d=1.203)$ outperformed the control group, but there was no difference between the immediate and delayed groups $(M D=$ $.065, p=.949, d=.403)$.

Table 2

Descriptive Statistics for the Grammaticality Judgment Test

\begin{tabular}{|c|c|c|c|c|c|c|c|c|c|c|}
\hline \multirow[t]{2}{*}{ Group } & \multicolumn{2}{|c|}{ Pretest } & \multicolumn{2}{|c|}{ Posttest I } & \multicolumn{2}{|c|}{ Posttest II } & \multicolumn{2}{|l|}{ Gain I } & \multicolumn{2}{|l|}{ Gain II } \\
\hline & $M$ & $S D$ & $M$ & $S D$ & $M$ & $S D$ & $M$ & $S D$ & $M$ & $S D$ \\
\hline Control $(n=15)$ & .20 & .14 & .20 & .13 & .26 & .13 & $.00(.04)$ & .11 & $.06(.06)$ & .12 \\
\hline Immediate $(n=15)$ & .20 & .19 & .46 & .19 & .49 & .19 & $.26(.20)$ & .23 & $.29(.30)$ & .19 \\
\hline Delayed $(n=13)$ & .22 & .13 & .44 & .21 & .48 & .20 & $.22(.20)$ & .11 & $.26(.23)$ & .19 \\
\hline
\end{tabular}

Finally, the ANCOVA model for grammaticality judgment gain II scores with the interaction term revealed no significant main effect for group, $F(2,37)=.39, p=.682, \eta^{2}=.006$, and a significant inhibitory control effect, $F(1,37)=7.19, p=.011, \eta^{2}=.058$. The interaction effect was not significant, $F(1,37)=.46, p=.633, \eta^{2}=.007$. The ANCOVA without the 
interaction term revealed a significant group effect, $F(2,39)=8.17, p=.001, \eta 2=.129$, and a significant inhibitory control effect, $F(1,39)=6.98, p=.012, \eta 2=.055$. Pairwise comparisons revealed that both the immediate $(M D=.235, p=.001, d=1.457)$ and delayed groups $(M D=$ $.160, p=.048, d=.992$ ) outperformed the control group, but there was no significant difference between the immediate and delayed groups $(M D=.075, p=.799, d=.465)$.

\section{Discussion and Conclusion}

This study explored the role of inhibitory control in the acquisition of Spanish nounadjective gender agreement under different feedback timing conditions. We carried out two types of analyses to determine the role of inhibitory control. In our first analysis, we tested whether there was an interaction between inhibitory control and feedback group. A statistically significant interaction between the two would have indicated a difference in the way inhibitory control is related to learning outcomes under different feedback timing conditions. Our results, however, did not show a significant interaction between inhibitory control and feedback group on either outcome measure even though the correlations between gain scores and inhibitory control seemed to be different across groups (see the Appendix). The correlation between oral production gains on posttest I was statistically significant only under the delayed condition. The lack of a significant interaction despite the difference in correlational patterns indicates that the strengths of the associations between inhibitory control and learning outcomes under different learning conditions were not reliably different from each other.

This finding fails to confirm our prediction that inhibitory control would play a more important role in the immediate feedback condition than in the delayed feedback condition. We predicted that learners receiving immediate feedback would give a short break to their processing for meaning in order to suppress the linguistic stimuli that were not needed for the interpretation 
of feedback and to focus their attention on the information provided through feedback. We did not expect a role for inhibitory control in the delayed feedback condition because the feedback was not provided during interaction in this condition. One explanation for this finding might relate to the nature of text-based SCMC through which the interactions between the learners and the native speaker took place. It has been argued that text-based SCMC heightens attention to form because it provides extra processing time to learners to allocate their attentional resources effectively by allowing messages to be read multiple times and by presenting information in the visual modality. These features might have reduced the cognitive burden of processing immediate feedback during meaning-based interaction, eliminating any need for inhibitory control.

The finding of the study about the lack of a relationship between inhibitory control ability and learning outcomes after receiving immediate reformulations diverges from the finding of Gass et al. (2013), which found a significant relationship between inhibitory control and learners' posttest performance after receiving interactional feedback. One factor that can potentially explain this finding is the difference between the two studies in communication mode (F2FC in Gass et al. and SCMC in the current study). Additionally, Gass et al. measured inhibitory control using the Stroop task, which uses both visual and verbal stimuli, whereas this study used the Flanker task, which relies on verbal stimuli only. It is possible that the similarity between the Stroop and language outcome measures in terms of stimulus modality might help this task capture the variation in learners' linguistic performance better. Future studies using both inhibitory control measures are needed to confirm this explanation.

Our second analysis aimed at determining whether inhibitory control played a role in learners' improvement from pretest to posttest regardless of feedback timing condition. This 
analysis showed that inhibitory control played a significant role in gain scores in oral production posttest I and grammaticality judgment posttest II. In both cases, the relationship was positive, as shown by the correlations in the Appendix. However, these positive correlations show an inverse relationship because higher Flanker scores indicate lower inhibitory control. In other words, learners with lower inhibitory control improved more from pretest to posttest. This indicates that learners with lower inhibitory control had higher gains in oral production posttest I and grammaticality judgment posttest II regardless of whether they received feedback or the timing of feedback. Given that the role of inhibitory control was the same for the control group as for the feedback groups, the inverse relationship between inhibitory control and learning gains was likely to be due to an interaction between inhibitory control and another factor that was relevant to the performance of all groups. One such factor could be learners' prior knowledge of the target structure. Gender agreement is a common instructional focus in Spanish classes, and it is possible that learners had received explicit information about the rule underlying this structure. Producing output during the treatment task might have activated this prior knowledge for all learners, but learners with low inhibitory control might have failed to block this knowledge during the posttests and relied on it instead of the knowledge that could have been obtained from their respective treatments. It is important to note that our finding regarding the inverse relationship between inhibitory control and learning outcomes needs future confirmation given the fact that inhibitory control explained only a small amount of variance (4\% and 6\%) in learners' scores as shown by eta squared values (oral production gain I, $\eta 2=.040$; grammaticality judgment gain II, $\eta 2=.055)$.

Finally, this study showed that immediate feedback was more effective than delayed feedback on the OPT after controlling for the effect of inhibitory control. This corroborates the 
findings of Arroyo and Yilmaz (2018), which also reported an advantage for immediate feedback on the OPT after analyzing the same data set without controlling for inhibitory control. Taken together, these results indicate that the effect of feedback timing on learners' oral production performance is robust and does not fluctuate according to learners' inhibitory control. The finding that immediate feedback is more effective than delayed feedback in the OPT even after controlling for inhibitory control lends further support to the focus on form perspective (Doughty, 2001; Doughty \& Long, 2003), which predicts an advantage for immediate over delayed feedback. Overall, it is possible to talk about the following pedagogical implications of our findings for CMC contexts. First, our study showed that inhibitory control was not predictive of learners' L2 gains after corrective feedback. This finding suggests that L2 learners' inhibitory control is not a factor that L2 instruction should take into account when providing immediate or delayed corrective feedback on learners' ungrammatical utterances. Second, immediate corrective feedback was more effective than delayed corrective feedback even after differences among learners in inhibitory control were taken into consideration. If this finding is confirmed by future research, it would be plausible to recommend that instruction include communicative tasks which provide learners with opportunities to receive immediate corrective feedback during interaction.

The scope of our study was limited in several ways. First, Spanish noun-adjective gender agreement, the linguistic target of the present study, has low communicative value. Clearly, the results cannot be generalized to other linguistic targets that do not share this feature. Second, inhibitory control was operationalized through the Flanker test, which relies solely on visual stimuli. Other inhibitory control tasks relying on both visual and verbal information (e.g., the Stroop or Simon task) might produce different results with respect to the role of inhibitory 
control. Third, corrective feedback in this study was operationalized as reformulations and was provided on errors that arose during text-based SCMC. The findings of this study may not be generalizable to contexts involving other types of corrective feedback (e.g., prompts) or to contexts where feedback is provided through face-to-face communication.

Despite these limitations, this study is the first to explore the role of inhibitory control in different feedback timing conditions, and thus makes a significant contribution to research investigating the interaction between cognitive abilities and instructional conditions. The results did not confirm our prediction that inhibitory control would play a more substantial role under the immediate feedback condition. Instead, it showed that inhibitory control was negatively related to learning outcomes under all conditions. It is important to note that this finding should be taken as provisional, given the low effect sizes for inhibitory control and the discrepancy between the findings of this study and a previous study (Gass et al., 2012). Clearly, further research is needed to determine the role of inhibitory control under different feedback conditions. 


\section{References}

Baddeley, A. D. (1986). Working memory. Oxford: Oxford University Press.

Baralt, M. (2013). The impact of cognitive complexity on feedback efficacy during online versus face-to-face interactive tasks. Studies in Second Language Acquisition, 35, 689-725.

Bartolotti, J., Marian, V., Schroeder, S. R., \& Shook, A. (2011). Bilingualism and inhibitory control influence statistical learning of novel word forms. Frontiers in Psychology, 2, 110.

Bower, J., \& Kawaguchi, S. (2011). Negotiation of meaning and corrective feedback in Japanese/English eTandem. Language, Learning \& Technology, 15. 41-71.

Bialystok, E., Martin, M. M., \& Viswanathan, M. (2005). Bilingualism across the lifespan: The rise and fall of inhibitory control. International Journal of Bilingualism, 9, 103-119.

Blake, R. J. (2000). Computer-mediated communication: A window on L2 Spanish interlanguage. Language Learning \& Technology, 4, 120-136.

Blumenfeld, H. K., \& Marian, V. (2011). Bilingualism influences inhibitory control in auditory comprehension. Cognition, 118, 245-257.

Costa, A., Hernández, M., \& Sebastián-Gallés, N. (2008). Bilingualism aids conflict resolution: Evidence from the ANT task. Cognition, 106, 59-86.

DeKeyser, R. (2012). Interactions between individual differences, treatments, and structures in SLA. Language Learning, 62, 189-200.

Doughty, C. (2001). Cognitive underpinnings of focus on form. In P. Robinson (Ed.), Cognition and second language instruction (pp. 206-57). Cambridge: Cambridge University Press,

Doughty, C.J., \& Long, M.H. (2003). Optimal psycholinguistic environments for distance foreign language learning. Language Learning \& Technology, 7, 50-80. 
Ellis, R., Loewen, S., \& Erlam, R. (2006). Implicit and explicit corrective feedback and the acquisition of L2 grammar. Studies in Second Language Acquisition, 28, 339-368.

Eriksen, B. A.; Eriksen, C. W. (1974). Effects of noise letters upon identification of a target letter in a non- search task. Perception and Psychophysics, 16, 143-149.

Gass, S., \& Mackey, A. (2006). Input, interaction and output: An overview. In K. Bardovi-Harlig \& Z. Dörnyei (Eds.), AILA Review, (pp. 3-17). Amsterdam: John Benjamins.

Gass, S., \& Lee, J. (2011). Working memory capacity, inhibitory control, and proficiency in a second language. In M. Schmid \& W. Lowie (Eds.), Modeling bilingualism: From structure to chaos (pp. 59-84). Amsterdam: John Benjamins.

Gass, S., Behney, J. N., \& Uzum, B. (2013). Inhibitory control, working memory and L2 interaction. Second Language Learning and Teaching, 7, 91-114.

Goo, J., Granena, G., Yilmaz, Y., \& Novella, M. (2015). Implicit and explicit instruction in L2 learning: Norris \& Ortega (2000) revisited and updated. In Rebuschat, P. (Ed.), Implicit and explicit learning of languages (pp. 443-482). Amsterdam: John Benjamins.

Granena, G., \& Yilmaz, Y. (2018). Corrective feedback and the role of implicit sequence learning ability in L2 online performance. Language Learning, 69, 127-156.

Gurzynski-Weiss, L., \& Baralt, M. (2014). Exploring learner perception and use of task-based interactional feedback in FTF and CMC modes. Studies in Second Language Acquisition, $36,1-37$.

Henderson, C. (2019). The effect of feedback timing on L2 Spanish vocabulary acquisition in synchronous computer-mediated communication. Advance online publication. Language Teaching Research. doi: 10.1177/1362168819832907 
Iwasaki, J., \& Oliver, R. (2003). Chat-line interaction and negative feedback. Australian Review of Applied Linguistics, 17, 60-73.

Jiang, N. (2012). Conducting reaction time research in second language studies. New York, NY: Routledge.

Kane, M. J. \& Engle, R. W. (2003). Working-memory capacity and the control of attention: The contributions of goal neglect, response competition, and task set to Stroop interference. Journal of Experimental Psychology: General, 132, 47-70.

Li, S. (2010). The Effectiveness of Corrective Feedback in SLA: A Meta-Analysis. Language Learning, 60, 309-365.

Li, S., Zhu, Y., \& Ellis, R. (2016). The effects of the timing of corrective feedback on the acquisition of a new linguistic structure. The Modern Language Journal, 100, 276-295.

Linck, J. A., \& Weiss, D. J. (2015). Can working memory and inhibitory control predict second language learning in the classroom? SAGE Open, October-December, 1-11.

Loewen, S., \& Erlam, R. (2006). Corrective feedback in the chatroom: An experimental study. Computer Assisted Language Learning, 19, 1-14.

Long, M. H. (1996). The role of the linguistic environment in second language acquisition. In W. Ritchie \& T. Bhatia (Eds.), Handbook of language acquisition: Second language acquisition (pp. 413-468). New York, NY: Academic Press.

Long, M. H. (2007). Recasts in SLA: The story so far. In M. Long (Ed.), Problems in SLA (pp. 75-116), Mahwah, N.J.: Lawrence Erlbaum.

Long, M. H, \& Robinson, P. (1998). Focus on form in classroom second language acquisition. New York, NY: Cambridge University Press.

Mackey, A., \& Goo, J. (2007). Interaction research in SLA: A meta-analysis and research 
synthesis. Mackey, In A. Mackey (Ed.), Conversational interaction in SLA: A collection of empirical studies (pp. 408-452). New York: Oxford University Press.

Nassaji, H. (2016). Researching corrective feedback in interaction and instruction. Language Teaching Research, 20, 433-435.

Norman, D.A., \& Shallice, T. (1986). Attention to action: Willed and automatic control of behavior. In R. Davidson, G. Schwartz, \& D. Shapiro, (Eds.), Consciousness and self regulation: Advances in research and theory: Vol. 4 (pp. 1-18). New York: Plenum

Quinn, P. (2014). Delayed versus immediate corrective feedback on orally produced passive errors in English (Unpublished doctoral dissertation). University of Toronto, Toronto.

Ranta, L. \& R. Lyster (2007). A cognitive approach to improving immersion students' oral language abilities: The awareness-practice-feedback sequence. In R. DeKeyser (Ed.), Practice in a second language: Perspectives from applied linguistics and cognitive psychology (pp. 141-160). Cambridge: Cambridge University Press.

Révész, A., \& Han, Z. (2006). Task content familiarity, task type and efficacy of recasts. Language Awareness, 15, 160-179.

Sachs, R., \& Suh, B.-R. (2007). Textually enhanced recasts, learner awareness, and L2 outcomes in synchronous computer-mediated interaction. In A. Mackey (Ed.), Conversational interaction in second language acquisition: A collection of empirical studies (pp. 199227). Oxford: Oxford University Press.

Schmidt, R. W. (2001). Attention. In P. Robinson (Ed.), Cognition and second language instruction (pp.3-32). New York: Cambridge University Press/

Shintani, N., \& Aubrey, S. (2016). The effectiveness of synchronous and asynchronous written corrective feedback on grammatical accuracy in a computer-mediated environment. 
Modern Language Journal, 16, 296-319.

Skehan, P. (1998). A cognitive approach to language learning. Oxford: Oxford University Press.

Smith, B. (2003). The use of communication strategies in computer-mediated communication. System, 31, 29-53.

Sotillo, S. M. (2000). Discourse functions and syntactic complexity in synchronous and asynchronous communication. Language Learning \& Technology, 4, 82-119.

Warschauer, M. (1997). Computer-mediated collaborative learning: Theory and practice. The Modern Language Journal, 81, 470-481.

Yilmaz, Y. (2011). Task effects on focus on form in synchronous computer-mediated communication. Modern Language Journal, 95, 115-132.

Yilmaz, Y. (2012). The relative effects of explicit correction and recasts on two target structures via two communication modes. Language Learning, 62, 1134-1169.

Yilmaz, Y. (2016). The linguistic environment, interaction and negative feedback. Brill Research Perspectives in Multilingualism and Second Language Acquisition, 1, 45-86.

Yilmaz, Y., \& Yuksel, D. (2011). Effects of communication mode and salience on recasts: A first exposure study. Language Teaching Research, 15, 457-477.

Yilmaz, Y., \& Granena, G. (2016). The role of cognitive aptitudes for explicit language learning in the relative effects of explicit and implicit feedback. Bilingualism: Language and Cognition, 19, 147-161.

Ziegler, N. (2015). Synchronous computer-mediated communication and interaction. Studies in Second Language Acquisition, 38, 558-586. 


\section{Appendix}

Correlations for OPT gains and inhibitory control

\begin{tabular}{|c|c|c|c|c|}
\hline \multirow[t]{2}{*}{ Group } & \multicolumn{2}{|c|}{ Gain I } & \multicolumn{2}{|c|}{ Gain II } \\
\hline & $r$ & $p$ & $r$ & $p$ \\
\hline Control $(n=15)$ & .19 & .50 & -.27 & .34 \\
\hline Immediate $(n=15)$ & .06 & .84 & -.34 & .22 \\
\hline Delayed $(n=13)$ & $.59 *$ & .03 & .50 & .08 \\
\hline
\end{tabular}

Note. ${ }^{*}$ Correlation is significant at the 0.05 level (2-tailed).

Correlations for GJT gains and inhibitory control

\begin{tabular}{|c|c|c|c|c|}
\hline \multirow[t]{2}{*}{ Group } & \multicolumn{2}{|c|}{ Gain I } & \multicolumn{2}{|c|}{ Gain II } \\
\hline & $r$ & $p$ & $r$ & $p$ \\
\hline Control $(n=15)$ & -.10 & .73 & .31 & .26 \\
\hline Immediate $(n=15)$ & .29 & .29 & .43 & .11 \\
\hline Delayed $(n=13)$ & .38 & .21 & .44 & .13 \\
\hline
\end{tabular}


Overall correlations between gain scores and inhibitory control

\begin{tabular}{|c|c|c|c|c|c|c|c|c|}
\hline \multirow[t]{2}{*}{ Group } & \multicolumn{2}{|c|}{ OPT Gain I } & \multicolumn{2}{|c|}{ OPT Gain II } & \multicolumn{2}{|c|}{ GJT Gain I } & \multicolumn{2}{|c|}{ GJT Gain II } \\
\hline & $r$ & $p$ & $r$ & $p$ & $r$ & $p$ & $r$ & $p$ \\
\hline All participants $(n=43)$ & .19 & .22 & -.13 & .40 & .18 & .26 & $.36^{*}$ & .02 \\
\hline
\end{tabular}

Note. * Correlation is significant at the 0.05 level (2-tailed). 